\title{
The German Unemployment Compensation System: Effects on Aggregate Savings and Wealth Distribution
}

\author{
Burkhard Heer* \\ University of Bamberg and CESifo, Munich
}

JEL classification: C68, D31, D91, H55

Key Words: Unemployment Compensation, Wealth Distribution, General Equilibrium, OLG

\begin{abstract}
:
The effects of the German unemployment compensation system on aggregate savings and the distribution of wealth are studied in a general equilibrium 60-period OLG model. The distribution of wealth is derived as an endogenous function of the parameters characterizing the unemployment compensation system, which comprises unemployment insurance $(A r$ beitslosengeld), unemployment assistance (Arbeitslosenhilfe), and welfare payments (Sozialhilfe), the latter two being subject to a means test. As our main results, (i) both aggregate savings and wealth equality are a monotone decreasing function of unemployment benefits. (ii) Optimal unemployment compensation declines over the spell of unemployment. (iii) Asset-based means tests are shown to reduce welfare if the allowable wealth level is below the average wealth in the economy.

${ }^{*}$ Corresponding address: University of Bamberg, Department of Economics, Feldkirchenstrasse 21, 96052 Bamberg, Germany, email: Burkhard.Heer@sowi.uni-bamberg.de

Preliminary versions of this paper have been presented at seminars and conferences in Cologne, Hamburg, Mainz, and Moscow. We would like to thank Michael Funke, Jan van Herden, Christian Keuschnigg, Bernd Lucke, Carl Christian von Weizsäcker, and two anonymous referees for their helpful comments on earlier versions of this paper. All remaining errors are ours.
\end{abstract}




\section{Introduction}

The German unemployment compensation system comprises three elements: unemployment insurance (Arbeitslosengeld), unemployment assistance (Arbeitslosenhilfe), and welfare payments (Sozialhilfe). In this paper, two important features of the German unemployment compensation system are highlighted: the benefit level and the asset-based means test. The effects of unemployment compensation on the wealth distribution are studied in a 60-period OLG general equilibrium model calibrated with regard to the characteristics of the West German economy. Unemployment compensation is financed by a proportional payroll tax. We find that German unemployment compensation reduces both aggregate savings and the equality of the wealth distribution. Importantly, optimal unemployment assistance payments are considerably lower than optimal unemployment insurance payments so that optimal unemployment compensation declines over time. In addition, asset limits imposed on the unemployed agents' allowable wealth in order to be entitled to unemployment compensation are shown to be harmful if the wealth limit is chosen below the average wealth in the economy.

The economy we study has three features that are crucial for evaluating the effect of unemployment compensation on the wealth distribution: i) individuals are subject to earnings uncertainty during their working life. Furthermore, insurance markets are incomplete. ii) Agents cannot borrow against anticipated future wages implying nonnegative net worth at all times and all ages. iii) The provision of unemployment assistance and welfare payments is subject to an asset-based means test. As a consequence, savings in our economy are different from the ones in the traditional life-cycle model as studied by e.g. Auerbach/Kotlikoff (1987). Various theoretical studies such as Drèze/Modigliani (1972), Miller (1976), or Sandmo (1970) to name but a few show that savings increase with the level of labor-income uncertainty whenever preferences are described by a separable utility function with convex marginal utility. Caballero (1991) demonstrates that a large part of wealth accumulation (up to 60\%) can be explained by the presence of earnings uncertainty. ${ }^{1}$ Borrowing constraints further increase aggregate wealth because they are most likely to bind for young agents effectively shifting consumption to later years in

\footnotetext{
${ }^{1}$ Other studies on the quantitative importance of precautionary savings include theoretical work by Skinner (1988), Hubbard et al. (1994), and Aiyagari (1994) and empirical work by Dardoni (1991). Carroll and Samwick (1995) provide a critical review of this literature.
} 
life (see e.g. Hubbard/Judd, 1987, and Aiyagari, 1994). The provision of unemployment compensation, however, reduces precautionary savings and alleviates liquidity constraints. Furthermore, and central to the question raised in this paper, the net effect of the provision of unemployment compensation on the distribution of wealth is not straightforward: on the one hand, unemployment compensation redistributes wealth from the rich to the poor. ${ }^{2}$ On the other hand, precautionary savings and savings due to liquidity constraints are likely to be reduced in a higher proportion among the poor than among the rich. The net effect can only be studied numerically in a parameterized general equilibrium model.

In order to focus on how changes in social security affect capital accumulation through its effect on precautionary savings, we treat employment as exogenous. A number of authors have addressed the effects of unemployment compensation in a life-cycle model with heterogenous agents and endogenous employment. These studies present an alternative modelling choice complementary to ours. In Hansen and Immrohoroğlu (1992), agents are offered a job with a certain probability. Agents value leisure and the agent can either accept or reject the employment offer. If an agent rejects the offer and gets detected, he does not receive unemployment insurance. Both the unemployed worker who has not received a job offer and the unemployed worker who has refused the job offer but is not detected receive unemployment compensation by the government. Unemployment insurance is financed by a tax on income. Hansen and İmrohoroğlu find that the optimal replacement ratio is very sensitive with regard to the moral hazard level. If the probability of an agent to reject an employment offer undetected and to receive unemployment insurance is zero, the optimal replacement ratio is as high as $65 \%$ for the US calibration. In the presence of moral hazard, however, the economy can be worse off with an unemployment insurance. Costain (1997) analyzes the effects of unemployment insurance on welfare and employment in a general equilibrium model with search unemployment. Following an increase in unemployment insurance benefits, agents increase their reservation wage and firms reduce their posting of vacancies. As a consequence, employment falls with rising unemployment insurance. Costain finds that UI payments only have a small impact on welfare, on the order of $0.1 \%$ of the baseline average consumption. Optimal replacement ratios of unemployment insurance are shown to be sensitive with regard to the degree of risk aversion.

Hubbard et al. (1995) study the effects of social insurance on precautionary savings in

\footnotetext{
${ }^{2}$ In this paper, when we talk about the rich, we refer to the wealth-rich.
} 
a life-cycle model with uncertain earnings. The provision of government transfers is subject to an asset-based means test. In addition, agents differ with regard to their education. Hubbard et al. demonstrate that social insurance depresses savings for two reasons. First, earnings uncertainty and hence the need for precautionary savings is reduced. And second, the means test provides a penalty on saving behavior, placing an implicit tax rate of 100 percent above the allowable wealth level for social security recipients. Furthermore, even the prospect of unemployment influences the savings behavior. For intermediate levels of wealth, households may switch from a policy of consuming all income to one with increased savings. Within this range of wealth, the marginal propensity to consume out of wealth can fall below zero. Hubbard et al. show that their life-cycle model with a social insurance program subject to an asset-based means test is able to replicate empirical wealth-age patterns.

Our model is most closely related to Hubbard et al. (1995). In accordance with them, we study a life-cycle model with heterogenous agents and borrowing constraints. Our model differs from the one of Hubbard et al. in two important ways: i) we study a general equilibrium. As a consequence, both the wage rate and the interest rate depend on accumulated wealth in our economy. Furthermore, we demand the government budget to balance at any time and additional expenditures on unemployment compensation are to be financed by an increase of the labor income tax rate. ii) The unemployment compensation system in our model is adapted to the German institutional characteristics, i.e. we distinguish unemployment insurance, unemployment assistance, and welfare payments, the latter two being subject to an asset-based means test. Hubbard et al., instead, assume that the government guarantees a minimum level of consumption. In addition to Hubbard (1995), we analyze the effects of a change in the asset limit.

The organisation of the paper is as follows. Section 2 shortly describes the unemployment compensation system in Germany. Section 3 introduces the model. In section 4, the model is calibrated with regard to characteristics of the German economy. In section 5 , our numerical results are presented. Section 6 concludes. 


\section{Unemployment Compensation in Germany}

Three forms of jobless pay can be distinguished in Germany: (i) unemployment insurance (Arbeitslosengeld, henceforth ALG), (ii) unemployment assistance (Arbeitslosenhilfe, henceforth ALH), and (iii) welfare payments (Sozialhilfe, henceforth SH). A concise description of the former two can be found in Hunt (1995) or Steiner (1997). The latter one is often missing from quantitative economic analyses, even though it is important in economic terms. In fact, the number of $\mathrm{SH}$ recipients has exceeded the one of ALG and ALH recipients for most of the past 20 years (source: Statististical Yearbook of the German Statistical Office, various issues); e.g. in 1995, 1.78 million people received ALG, 0.98 million people ALH, and 2.55 million people $\mathrm{SH}$ (where $55.4 \%$ of the SH recipients are aged between 18-65). In this section, only the features of the German unemployment insurance system with relevance to our model in the following section are presented and one necessary simplifying assumption of our model is pointed out.

(i) Unemployed workers receive unemployment insurance (ALG) if they have been employed for at least 12 months during the last 3 years. Unemployed agents receive a maximum of $67 \%$ of the previous net monthly wage for a period up to 1 year. Agents exceeding age 42 may receive longer benefits up to 3 years. Steiner (1997) and Hunt (1995) apply values of about 9 and 14 months for the potential entitlement period, respectively. In accordance with these studies, we will assume that unemployment insurance is paid for exactly one year following the unemployment spell to all agents irrespective of their employment history.

(ii) Unemployed workers receive unemployment assistance (ALH) if they have lost entitlement to unemployment insurance (ALG) in the previous 12 months or if they have received unemployment assistance the year before. Unemployed agents receive a maximum of $57 \%$ of the previous net monthly wage. ALH payments are reduced by other income, e.g. interest income, and ALH cases are reviewed once a year and are subject to an assetbased means test. If the agent's wealth exceeds a certain limit, he is not entitled to ALH payments. Basically, unemployment assistance is granted without any time limit with only a few exceptions. One of these exceptions with relevance to our model is the loss of ALH entitlement as a consequence of the means test. According to German law 
(Arbeitsförderungsgesetz $\$ 135,1),{ }^{3}$ agents are no longer entitled to ALH if they have not received ALH for more than one year. ${ }^{4}$

(iii) Welfare payments are conceived to prevent people from poverty and are distributed subject to the Nachrangig-principle i.e. SH is disbursed to an unemployed agent if and only if any other source of income has been used up before. As a consequence, all net income is deducted from SH payments and welfare payments $\mathrm{SH}$ are only paid to those workers who are neither eligible for unemployment insurance nor unemployment assistance. In the case of our model, there are only two kinds of unemployed agents qualifying for welfare payments: those agents who have never found a job during their lifetime and those who were ineligible for unemployment assistance some time in the past because of the means test and have since then consumed their wealth. SH benefits are subject to a means test, too. The mean value of current monthly SH payments to an unemployed agent amounts to approximately 520 DM in 1998, depending on the state (Bundesland) he/she resides in. Furthermore, SH also provides health insurance and covers the rent. ${ }^{5}$

\section{The Model}

In our economy, three sectors are depicted: the household sector, the production sector, and the government. Households live for 60 years and maximize discounted life-time utility. They inherit no wealth and they do not leave any bequests. The sixty period life span is intended to correspond approximately to the life span of an adult, that is, the years between 21 and 80. Agents can either be employed or unemployed during their working life. If unemployed, agents search for a job and the probability to find a job depends on their age. In old age, they recieve public pensions. Firms maximize profits. Output

\footnotetext{
${ }^{3}$ On 1.1.1998, the German job promotion law (Arbeitsförderungsgesetz) was integrated in the Sozialgesetzbuch SGB.

${ }^{4}$ There are exemptions from this period length of one year in the present law. In particular, according to $\S 192,2$, SGB III, the unemployed worker is entitled to ALH if he has received ALG for one day during the last three years but has not received ALH thereafter because of the means test.

${ }^{5}$ In Germany, unemployment compensation is paid for by the federal government (Bundesanstalt für Arbeit), while welfare is paid for by the municipal government. We neglect the vertical structure of the German jurisdictions. Feist and Schöb (1999) analyze recent reform proposals of the German welfare payment system in the presence of vertical fiscal externalities.
} 
is produced with the help of labor and capital. The government provides unemployment compensation which is financed by a tax on wage income. Since we will only analyze steadystate allocations, the time index is omitted from the variables. Time periods correspond to years.

\subsection{Households}

Households live for $T+T^{R}=60$ periods. The first $T=40$ periods, agents are workers supplying labor inelastically. At age 41, retirement is mandatory and the remaining lifetime is set equal to $T^{R}=20$. Each generation of age $t$ is of equal measure and the measure of all households is normalized to one.

Agents are heterogenous with regard to their age $t$, their wealth $k$, their productivity $\eta_{j, t}$, and their employment status $\epsilon$. Agents are born with different skill levels $j$, and productivity $\eta_{j, t}$ depends on both the skill level $j, 1 \leq j \leq n_{j}$, and age $t$. The skill level $j$ is assumed to be deterministic so that agents have the same skill for the whole lifetime. In addition, productivity is age-dependent and will follow a hump-shaped path over the life cycle in our calibrated model. We assume that each productivity class is of equal measure.

The household maximizes his intertemporal utility:

$$
\max _{c_{t}} E \sum_{t=1}^{T+T^{R}} \beta^{t-1} \frac{c_{t}^{1-\sigma}-1}{1-\sigma},
$$

where $c_{t}$ denotes the consumption of the $t$-year household. $\sigma$ and $\beta$ are the coefficient of relative risk aversion and the discount factor, respectively, and expectations $E$ are taken conditional on information at the beginning of age $t$. The information set of the household includes his employment status $\epsilon$ at age $t$, his capital stock $k$ at the beginning of the period ${ }^{6}$ and his skill type $j$.

Furthermore, workers face a risk of unemployment, but cannot insure privately against it. Five different kinds of households with employment status $\epsilon \in\{1, \ldots, 5\}$ can be distinguished: $\epsilon=1$ ) employed agents of measure $n$, who receive wage $w$ per efficiency unit

\footnotetext{
${ }^{6}$ Since capital $k$ is the only asset held by individuals, the terms capital and wealth will henceforth be used interchangeably.
} 
$\eta_{j, t}$, taxed at rate $\tau, \epsilon=2$ ) short-term unemployed agents of measure $n_{U I}$, who were employed a year ago and receive unemployment insurance $w_{U I}$ per efficiency unit $\eta_{j, t}, \epsilon=3$ ) long-term unemployed agents of measure $n_{U A}$, who were not employed a year ago and are entitled to unemployment assistance $w_{U A}$ per efficiency unit $\eta_{j, t}$ (subject to a means test), $\epsilon=4)$ long-term unemployed agents of measure $n_{W}$, who are not entitled to unemployment assistance because they have not been employed before at all or because they have lost entitlement to unemployment assistance as a result of the means test, and $\epsilon=5$ ) retired people of measure $n_{R}$ with pension payments $w_{R, j}$.

Unemployment insurance $w_{U I} \eta_{j, t}$ is paid to all short-term unemployed workers irrespective of their wealth and their non-labor income and is proportional to the income of the employed agent with the same age $t$ and skill level $j .^{7}$ In order to receive unemployment assistance, household wealth $k$ has to be below $k_{U A}^{m a x}$. The long-term unemployed agents who are not entitled to unemployment assistance $(\epsilon=4)$ receive welfare payments $w_{W}$ subject to a means test, i.e. if their wealth $k$ is below $k_{W}^{\max }$. Contrary to unemployment insurance and unemployment assistance payments, welfare payments $w_{W}$ are lump-sum and do not depend on previous earnings or the productivity level of the agent. Furthermore, all other non-labor income of the household is deducted from both unemployment assistance and welfare payments. Accordingly, the non-capital income $y(k, \epsilon, j, t)$ of a $t$-year old household with capital $k$, employment status $\epsilon$, and skill level $j$ is given by:

$$
y(k, \epsilon, j, t)= \begin{cases}(1-\tau) w \eta_{j, t} & \epsilon=1 \\ w_{U I} \eta_{j, t} & \epsilon=2 \\ \max \left(w_{U A} \eta_{j, t}-r k, 0\right) & \epsilon=3, k \leq k_{U A}^{\max } \\ 0 & \epsilon=3, k>k_{U A}^{\max } \\ \max \left(w_{W}-r k, 0\right) & \epsilon=4, k \leq k_{W}^{\max } \\ 0 & \epsilon=4, k>k_{W}^{\max } \\ w_{R, j} & \epsilon=5 .\end{cases}
$$

Pension payments $w_{R, j}$ depend on the individuals life-time earnings and are proportional

\footnotetext{
${ }^{7}$ In Germany, unemployment insurance depends on the wage earned during the last period of employment. In order to keep the model tractable and economize on the number of state variables, we make the simplifying assumption that unemployment insurance depends on the productivity during the current period rather than the productivity during the last period of employment. The same simplifying assumption is applied to the computation of unemployment assistance.
} 
to average productivity of the skill class $j$ during working life, $\bar{\eta}_{j}=\frac{1}{T} \sum_{t=1}^{T} \eta_{j, t}{ }^{8}$

Agents are born without any assets. Furthermore, agents are not allowed to borrow, $k \geq 0$. Depending on his employment status $\epsilon$, his capital holdings $k$, and his skill type $j$, an agent of age $t$ receives non-capital income $y(k, \epsilon, j, t)$ and earns interest income at rate $r$ :

$$
k^{\prime}+c=(1+r) k+y(k, \epsilon, j, t)
$$

where $k^{\prime}$ denotes next period's capital holdings.

During his working life, an agent finds employment with probability $p(t)$. Notice that the probability to find a job is a function of the age $t$ of the unemployed agent. Employed workers get separated from a job with probability $\theta$. Let $\phi(k, \epsilon, j, t)$ denote the measure of $t$-year old households with skill level $j$, wealth $k$, and employment status $\epsilon$ implying:

$$
\begin{aligned}
n & \equiv \sum_{t=1}^{T} \sum_{j=1}^{n_{j}} \int_{0}^{\infty} \phi(k, 1, j, t) d k \\
n_{U I} & \equiv \sum_{t=1}^{T} \sum_{j=1}^{n_{j}} \int_{0}^{\infty} \phi(k, 2, j, t) d k \\
n_{U A} & \equiv \sum_{t=1}^{T} \sum_{j=1}^{n_{j}} \int_{0}^{\infty} \phi(k, 3, j, t) d k \\
n_{W} & \equiv \sum_{t=1}^{T} \sum_{j=1}^{n_{j}} \int_{0}^{\infty} \phi(k, 4, j, t) d k \\
1 & =\sum_{\epsilon=1}^{5} \sum_{t=1}^{T+T^{R}} \sum_{j=1}^{n_{j}} \int_{0}^{\infty} \phi(k, \epsilon, j, t) d k \\
\frac{T^{R}}{T+T^{R}} & =\sum_{t=T+1}^{T+T^{R}} \sum_{j=1}^{n_{j}} \int_{0}^{\infty} \phi(k, 5, j, t) d k \equiv n_{R} .
\end{aligned}
$$

\subsection{Government}

The government uses the revenues from taxing labor in order to finance its expenditures on unemployment insurance, $g_{U I}$, unemployment assistance, $g_{U A}$, welfare, $g_{W}$, and pensions,

\footnotetext{
${ }^{8}$ In Germany, pensions depend on the individual's lifetime contribution to the pension system, and we make the simplifying assumption that agents of the same skill level $j$ have contributed equal amounts to the pension system. Furthermore, we do not model the redistributional features of the German pension system. For a welfare analysis of the German public pension system see Fehr (1999).
} 
$g_{R}:$

$$
\tau w N=g_{U I}+g_{U A}+g_{W}+g_{R}
$$

where

$$
\begin{aligned}
g_{U I} & =\sum_{t=1}^{T} \sum_{j=1}^{n_{j}} \int_{0}^{\infty} y(k, 2, j, t) \phi(k, 2, j, t) d k, \\
g_{U A} & =\sum_{t=1}^{T} \sum_{j=1}^{n_{j}} \int_{0}^{\infty} y(k, 3, j, t) \phi(k, 3, j, t) d k, \\
g_{W} & =\sum_{t=1}^{T} \sum_{j=1}^{n_{j}} \int_{0}^{\infty} y(k, 4, j, t) \phi(k, 4, j, t) d k, \\
g_{R} & =\sum_{t=T+1}^{T+T^{R}} \sum_{j=1}^{n_{j}} \int_{0}^{\infty} y(k, 5, j, t) \phi(k, 5, j, t) d k,
\end{aligned}
$$

and $N$ denotes the aggregate effective labor

$$
N=\sum_{t=1}^{T} \sum_{j=1}^{n_{j}} \eta_{j, t} \int_{0}^{\infty} \phi(k, 1, j, t) d k .
$$

The government chooses the parameters $w_{U I}, w_{U A}, w_{W}$, and $w_{R}$ together with $k_{U A}^{\max }$ and $k_{W}^{\max }$, while the labor income tax rate $\tau$ adjusts in order to guarantee a balanced budget.

\subsection{Firms}

Firms are of measure one and produce output with effective labor $N$ and aggregate capital $K$. Effective labor $N$ is paid the wage $w$. Capital $K$ is hired at rate $r$ and depreciates at rate $\delta$. Production is characterized by constant returns to scale and assumed to be Cobb-Douglas:

$$
F(K, N)=A_{0} K^{\alpha} N^{1-\alpha}
$$

In a factor market equilibrium, factors are rewarded with their marginal products:

$$
\begin{aligned}
r & =A_{0} \alpha\left(\frac{N}{K}\right)^{1-\alpha}-\delta \\
w & =A_{0}(1-\alpha)\left(\frac{K}{N}\right)^{\alpha} .
\end{aligned}
$$




\subsection{Steady State}

The concept of equilbrium used in this paper uses a recursive representation of the consumer's problem following Stokey et al. (1989). Let $V(k, \epsilon, j, t)$ be the value of the objective function of a $t$-year old agent of skill type $j$ with beginning-of-period asset holdings $k$ and employment status $\epsilon$. $V(k, \epsilon, j, t)$ is defined as the solution to the dynamic program:

$$
V(k, \epsilon, j, t)=\max _{c, k^{\prime}}\left[\frac{c^{1-\sigma}-1}{1-\sigma}+\beta E\left\{V\left(k^{\prime}, \epsilon^{\prime}, j, t+1\right)\right\}\right],
$$

subject to the budget constraint (3). E denotes the expectation operator conditional on information at the beginning of age $t$, and $\epsilon^{\prime}$ is the next-period employment status.

\section{Definition}

A steady state for a given set of government policy parameters

$\Omega=\left\{w_{U I}, w_{U A}, w_{W}, w_{R}, k_{U A}^{\max }, k_{W}^{\max }\right\}$ is a collection of value functions $V(k, \epsilon, j, t)$, individual policy rules $c(k, \epsilon, j, t), k^{\prime}(k, \epsilon, j, t)$, age-dependent, time-invariant measures of agent types $\phi(k, \epsilon, j, t)$ for each generation of age $t=1,2, \ldots, T+T^{R}$, relative prices of labor and capital $\{w, r\}$, such that:

1. Individual and aggregate behavior are consistent, and the aggregate capital stock $K$ is given by

$$
K=\sum_{t=1}^{T+T^{R}} \sum_{j=1}^{n_{j}} \sum_{\epsilon=1}^{5} \int_{0}^{\infty} \phi(k, \epsilon, j, t) \cdot k d k
$$

2. Relative prices $\{w, r\}$ solve the firm's optimization problem by satisfying (17) and (18).

3. Given relative prices $\{w, r\}$ and the government unemployment compensation policy $\Omega$, the individual policy rules $c($.$) and k^{\prime}($.$) solve the consumer's dynamic program$ (19).

4. The goods market clear:

$$
A_{0} K^{\alpha} N^{1-\alpha}=\sum_{t=1}^{T+T^{R}} \sum_{j=1}^{n_{j}} \sum_{\epsilon=1}^{5} \int_{0}^{\infty} c(k, \epsilon, j, t) \phi(k, \epsilon, j, t) d k+\delta K .
$$

5. Let $B$ be a subset of the domain of $k$ and $I(B, k, \epsilon, j, t)$ be an indicator function that takes the value one if $k^{\prime}(k, \epsilon, j, t) \in B$ and zero otherwise. The collection of age-dependent, time-invariant measures $\phi(B, \epsilon, j, t)$ satisfies the following transition equations for 
- the measure of the employed workers in $t \in\{1, \ldots, T-1\}$ :

$$
\begin{aligned}
\phi(B, 1, j, t+1)= & (1-\theta) \int_{0}^{\infty} I(B, k, 1, j, t) \phi(k, 1, j, t) d k \\
& +p(t) \sum_{\epsilon \in\{2,3,4\}} \int_{0}^{\infty} I(B, k, \epsilon, j, t) \phi(k, \epsilon, j, t) d k,
\end{aligned}
$$

- the measure of unemployment insurance recipients in $t \in\{1, \ldots, T-1\}$ :

$$
\phi(B, 2, j, t+1)=\theta \int_{0}^{\infty} I(B, k, 1, j, t) \phi(k, 1, j, t) d k,
$$

- the measure of unemployment assistance recipients in $t \in\{1, \ldots, T-1\}$ :

$$
\begin{aligned}
\phi(B, 3, j, t+1)= & (1-p(t)) \int_{0}^{\infty} I(B, k, 2, j, t) \phi(k, 2, j, t) d k \\
& +(1-p(t)) \int_{0}^{k_{U A}^{\max }} I(B, k, 3, j, t) \phi(k, 3, j, t) d k
\end{aligned}
$$

- the measure of welfare payment recipients in $t \in\{1, \ldots, T-1\}$ :

$$
\begin{aligned}
\phi(B, 4, j, t+1)= & (1-p(t)) \int_{k_{U A}^{\max }}^{\infty} I(B, k, 3, j, t) \phi(k, 3, j, t) d k \\
& +(1-p(t)) \int_{0}^{\infty} I(B, k, 4, j, t) \phi(k, 4, j, t) d k,
\end{aligned}
$$

- and the measure of retired agents in $t \in\left\{T+1, \ldots, T+T^{R}-1\right\}$ :

$$
\phi(B, 5, j, t+1)=\int_{0}^{\infty} I(B, k, 5, j, t) \phi(k, 5, j, t) d k .
$$

The distribution of the new-born generation and the first-year retired are given by:

$$
\begin{aligned}
\phi(k, \epsilon, j, 1) & = \begin{cases}\frac{p(1)}{T+T^{R}} \frac{1}{n_{j}} & \epsilon=1, k=0 \\
\frac{1-p(1)}{T+T^{R}} \frac{1}{n_{j}} & \epsilon=4, k=0 \\
0 & \text { else }\end{cases} \\
\phi(B, 5, j, T+1) & =\sum_{\epsilon=1}^{4} \int_{0}^{\infty} I(B, k, \epsilon, j, T) \phi(k, \epsilon, j, T) d k .
\end{aligned}
$$

In particular, the measures $\phi($.$) are time invariant so that the current measure$ $\phi(B, \epsilon, j, t)$ is equal to the next-period measure $\phi^{\prime}(B, \epsilon, j, t)$ for every subset $B$ of the domain of $k$, and every $\epsilon, j$, and $t$.

6. The government budget (10) is balanced. 


\subsection{Measures of Distribution and Welfare}

In section 5, we compare alternative unemployment compensation schemes quantifying the effects on distribution and welfare. The equality of wealth distribution is measured by the gini coefficient. ${ }^{9}$ Our measure of welfare for given policy arrangement $\Omega$ is the expected discounted utility of the newborn generation:

$$
W(\Omega)=\sum_{\epsilon=1}^{4} \sum_{j=1}^{n_{j}} \phi(0, \epsilon, j, 1) V(0, \epsilon, j, 1) .
$$

As our reference economy, we take an economy with full unemployment insurance and no means test. For such an economy, it is straightforward to compute the consumption stream of the different skill types $j,\left\{\tilde{c}_{t}^{j}\right\}_{t=1}^{T+T^{R}}$ of the newborn generation and hence welfare $\tilde{W}$ in this economy as each $t$-year old agent in every skill class $j$ behaves identically. The change in welfare resulting from an unemployment compensation program $\Omega$ is measured by the consumption equivalent increase $\delta_{c}$ such that $W(\Omega)$ is equal to the welfare implied by a consumption path $\left\{\left(1+\delta_{c}\right) \tilde{c}_{t}^{j}\right\}_{t=1}^{T+T^{R}}$ for the skill types $j=1, \ldots, n_{j}$.

One word of caution is warranted at this point. In our steady-state welfare comparisons, we neglect any welfare effects on the different cohorts during the transition from the old to the new steady state. For example, a lower unemployment compensation is likely to increase precautionary savings, and the capital intensity and production will be higher in the new steady state. After a once-and-for-all reduction of unemployment compensation payments, the capital intensity and the wage slowly increase to their new steady-state values. As a consequence, retired agents' pensions also increase during the transition, while the interest income on their accumulated savings falls. Accordingly, the cohort welfare during the transition may be markedly different from the one in the new steady state and some generations may gain, while others may loose during the transition to the new steady state. ${ }^{10}$

\footnotetext{
${ }^{9} \mathrm{As}$ an alternative measure, we also provide the coeffient of variation which is more sensitive to the tails of the distribution, in particular the longer upper tail of the wealth distribution.

${ }^{10}$ As one of the early studies that explicitly considers the transition between steady states in a life-cycle model, Auerbach et al. (1983) analyze the effects of a sudden once-and-for-all change in the consumption and wage tax rate on the intergenerational redistribution. They demonstrate that the welfare gains and losses of younger, older, and unborn generations differ substantially for the individual tax regimes.
} 


\section{Calibration}

The steady state distribution of wealth and employment and the effects of a change in the unemployment compensation system on welfare and distribution cannot be studied analytically but only numerically. For this reason, the model is calibrated in order to match characteristics of the West German economy. ${ }^{11}$ The time series data refer to the period 1993-94. The annual data on the unemployment rate, the number of unemployed males and females, ALG, ALH, and SH benefits are taken from the yearbooks of the German Statistical Office (Statistisches Bundesamt). The data on the means-tests of the ALH and SH benefits are provided by the German Federal Health Department (Bundesgesundheitsministerium). The data on the capital-output ratio is taken from Statistisches Bundesamt, Fachserie 18.

\section{Households}

Empirical estimates of the intertemporal elasticity of substitution $1 / \sigma$ vary considerably. The most widely used approach to estimate $1 / \sigma$ is based on the household's first-order condition of her/his intertemporal optimization calculus. While Campbell/Mankiw (1989) find rather small values of $1 / \sigma$ below 0.1, Beaudry/van Wincoop (1996) find values in the range 0.25-0.4. Attansio/Weber $(1993,1995)$ apply US household data rather than US aggregate data and estimate values of $1 / \sigma$ in the range between 0.33 and 0.66 . For German aggregate data, Flaig (1988) estimates values between 0.4 and 0.75 . In accordance with the latter studies, we will assume a coefficient of relative risk aversion $\sigma=2$ in our benchmark case. ${ }^{12}$ The discount factor $\beta$ is calibrated with the help of observations on the capital-output ratio. In the years 1991-97, the ratio of the capital stock to annual GDP was equal to 5.0 (2.6) in Germany for the total economy (producing sector). Targeting a capital-output ratio of approximately $K / A_{0} K^{\alpha} N^{1-\alpha}=4$, the household's discount factor

\footnotetext{
${ }^{11}$ The focus on West Germany rather than the whole Germany is caused by the facts that i) empirical results for specific labor market parameters of this model and for the wealth distribution are only available for West Germany, and ii) the East German economy is not close to a steady state in the calibration period 1993-94; e.g. Biewen (2000) shows that the income inequality has changed in East Germany during 1990-96 but not in West Germany.

${ }^{12}$ All our qualitative results are insensitive with regard to the choice of the parameters $\sigma \in\{1,2,4\}$ and $\beta \in\{0.97,0.99,1.01\}$.
} 
Table 1: Calibration of the efficiency parameter $\kappa_{i}^{j}$

\begin{tabular}{lccc} 
& $\kappa_{0}^{j}$ & $\kappa_{1}^{j}$ & $\kappa_{2}^{j}$ \\
\hline & & & \\
lowest quintile, $j=1$ & 0.327 & 0.045 & -0.00072 \\
second quintile, $j=2$ & 0.362 & 0.046 & -0.00073 \\
third quintile, $j=3$ & 0.442 & 0.049 & -0.00075 \\
fourth quintile, $j=4$ & 0.596 & 0.052 & -0.00078 \\
top quintile, $j=5$ & 0.805 & 0.062 & -0.00089 \\
\hline
\end{tabular}

is set equal to $\beta=0.99$. In our benchmark economy, the capital-output ratio amounts to 4.02 with a corresponding real interest rate equal to $4.64 \%$.

With regard to the calibration of the productivity $\eta_{j, t}$, we distinguish $n_{j}=5$ skill classes of the households. The productivity profile of the $n_{j}$ lifetime income classes is taken from Fehr (1999) and normalized so that the average efficiency in the economy is equal to one. ${ }^{13}$ In particular, the $\log$ of the efficiency index $\eta_{j, t}$ is specified as a quadratic function of age $t, \eta_{j, t}=\kappa_{0}^{j} e^{\kappa_{1}^{j} t+\kappa_{2}^{j} t^{2}}$. Table 1 summarizes the choice of the parameters $\kappa_{i}^{j}, i=0,1,2$, $j=1, \ldots, 5$.

\section{Government}

The government provides unemployment compensation. Previous estimates of West German replacement ratios, henceforth defined as the ratio of net benefits received in unemployment to net earnings received at work, vary considerably. Replacement ratios computed by the OECD (1996) are sensitive with regard to the household composition. In 1994, couples with no children received $60 \%$ of benefits relative to their net earnings in the first month of unemployment, while couples with two children and housing benefits received even $88 \%$ of net earnings (for the average production worker). After 5 years of unemployment, these numbers drop to $37 \%$ and $71 \%$, respectively. According to a Centre d'Etude des Revenus et des Coûts (CERC) study of European unemployment programs cited by Burtless (1987), replacement ratios drop from $66 \%$ to $56 \%$ from the first to the second year of unemployment for the agent who earned the average wage. For the agents

\footnotetext{
${ }^{13} \mathrm{Fehr}$ (1999) shows that this calibration of the income process is able to replicate the German net labor income distribution very accurately.
} 
who earned twice the average wage, these numbers fall to $51 \%$ and $44 \%$, respectively. ${ }^{14}$ Steiner (1997) computes the replacement ratio with respect to expected net wage yielding a mean value of 0.5 for those receiving ALG between 1983 and 1994. In accordance with the latter two studies, the replacement ratio of ALG and ALH are set equal to $50 \%$ and $44 \%$ in the benchmark case, respectively, but a sensitivity analysis of $w_{U I}$ and $w_{U A}$ is performed in section 5 as well. Welfare payments are computed from the ratio of average current $\mathrm{SH}$ expenditures, multiplied by a factor of 1.5 in order to correct for rent and health insurance payments provided by the local government, to net average income of a production worker. The SH replacement ratio is set equal to $30 \%$ of the average wage in the lowest income quintile, $w \bar{\eta}_{1} \cdot{ }^{15}$

As emphasized in section 2, unemployment assistance (ALH) and welfare payments (SH) are subject to a means test (Bedürftigkeitsprüfung). In 1997, ALH benefits are reduced or cancelled if household wealth exceeds 8,000 DM, which is less than the 3 -month net income of the average industrial worker in Germany. Similarly, a couple with 3 children may own 5,200 DM in order to be entitled to maximum SH payments. However, certain forms of assets are exempted from the means tests, e.g. inherited personal belongings, a car (if it is necessary to drive your children to the kindergarten, for example), estate or privately-owned houses (up to a certain value ranging from 400,000 DM to 700,000 DM depending on the location). ${ }^{16}$ In a first approximation, the maximum wealth levels $k_{W}^{\max }$ and $k_{U A}^{\max }$ are calibrated to be one times and $8000 / 5200=1.54$ times the average annual net wage in the economy, respectively. In addition, a sensitivity analysis with regard to these two parameters is performed.

The replacement ratio of public pension payments relative to net average earnings of each income class over the life cycle is set equal to $50 \%$. This value is in line with previous studies from Fehr (1997) and Chauveau/Loufir (1997). Fehr (1997) studies the tax and pension reforms proposed in 1997 and assumes that pensions are approximately $70 \%$ of

\footnotetext{
${ }^{14} \mathrm{At}$ the time of the CERC study, the maximum benefit of unemployment insurance and unemployment assistance amounted to $68 \%$ and $58 \%$ of net earnings, respectively.

${ }^{15}$ Almost the same number results from a computation using average expenditures of local governments for welfare payments relative to average expenditures of the federal government for unemployment insurance, after correcting the former for payments to disabled people (health risk is not considered in our model).

${ }^{16}$ To the best of our knowledge, there is no data on the wealth of German unemployment assistance and welfare recipients.
} 
average net income and are further taxed at the rate of 40\%, while Chauveau/Loufir (1997) take a value of 0.55 for the pension replacement ratio in Germany for the time period 198589. The income $\operatorname{tax} \tau$ is calculated from the government budget (10). The calibration of the model's parameters is summarized in table 2.

\section{Production}

The production parameters are taken from Heer/Linnemann (1998). The production elasticity of capital is set equal to $\alpha=0.35$. $A_{0}$ is normalized to one. The annual depreciation in Germany amounts to $\delta=0.04$.

\section{Labor Market}

Unemployed workers have different probabilities to find a job depending on their age $t$. The probabilities are taken from Steiner (1997) who provides estimates of the survival rates of males and females in 1993 through 1994 for different ages. Steiner uses data from the Socio-Economic Panel for West Germany (GSOEP). The probabilities presented in table 2 are averages of the survival rates provided by Steiner, weighted by the share of males and females among the unemployed, respectively. Notice that the probability to find a job declines monotonically with the age of the unemployed agent. The job separation probability $\theta$ is calibrated in order to give the West German unemployment rate during 1993-94, which is equal to $9.25 \%$.

\section{Results}

Our results are described for alternative policy programs characterizing the unemployment compensation system in Germany. First, equilibrium properties of the benchmark case are illustrated. Second, the effects of a change in the replacement ratios of unemployment insurance, unemployment assistance, and welfare payments on savings and distribution are presented. And third, the eligibility criterion of the German unemployment compensation system is analyzed. 
Table 2: Calibration of parameter values for West Germany 1993-94

\begin{tabular}{|c|c|c|}
\hline Description & Function & Parameter \\
\hline utility function & $U=\frac{c^{1-\sigma}-1}{1-\sigma}$ & $\sigma=2$ \\
\hline discount factor & $\beta$ & $\beta=0.99$ \\
\hline production function & $y=A_{0} k^{\alpha} n^{1-\alpha}$ & $\alpha=0.35, A_{0}=1$ \\
\hline depreciation & $\delta$ & $\delta=0.04$ \\
\hline job separation rate & $\theta$ & $\theta=4.46 \%$ \\
\hline $\begin{array}{l}\text { job finding rate } \\
\text { age }<5 \\
5 \leq \text { age } \leq 21 \\
22 \leq \text { age } \leq 24 \\
24 \leq \text { age } \leq 29 \\
29 \leq \text { age } \leq 34 \\
34 \leq \text { age } \leq 39\end{array}$ & $\begin{array}{l}p(.) \\
p(.) \\
p(.) \\
p(.) \\
p(.) \\
p(.)\end{array}$ & $\begin{array}{l}79.1 \% \\
65.7 \% \\
56.4 \% \\
50.2 \% \\
36.1 \% \\
16.5 \%\end{array}$ \\
\hline $\begin{array}{l}\text { unemployment insurance } \\
\text { unemployment assistance } \\
\text { welfare payments } \\
\text { pension payments }\end{array}$ & $\begin{array}{l}w_{U I} \\
w_{U A} \\
w_{W} \\
w_{R}\end{array}$ & $\begin{array}{l}w_{U I} /(1-\tau) w=50 \% \\
w_{U A} /(1-\tau) w=44 \% \\
w_{W} /(1-\tau) w \bar{\eta}_{1}=30 \% \\
w_{R} /(1-\tau) w=50 \%\end{array}$ \\
\hline $\begin{array}{l}\text { asset limit } \\
\text { unemployment assistance } \\
\text { welfare payments }\end{array}$ & $\begin{array}{l}k_{U A}^{\max } \\
k_{W}^{\max }\end{array}$ & $\begin{array}{l}k_{U A}^{\max }=1.54(1-\tau) w \\
k_{W}^{\max }=(1-\tau) w\end{array}$ \\
\hline
\end{tabular}


Figure 1: Consumption policy of a 20-year old worker

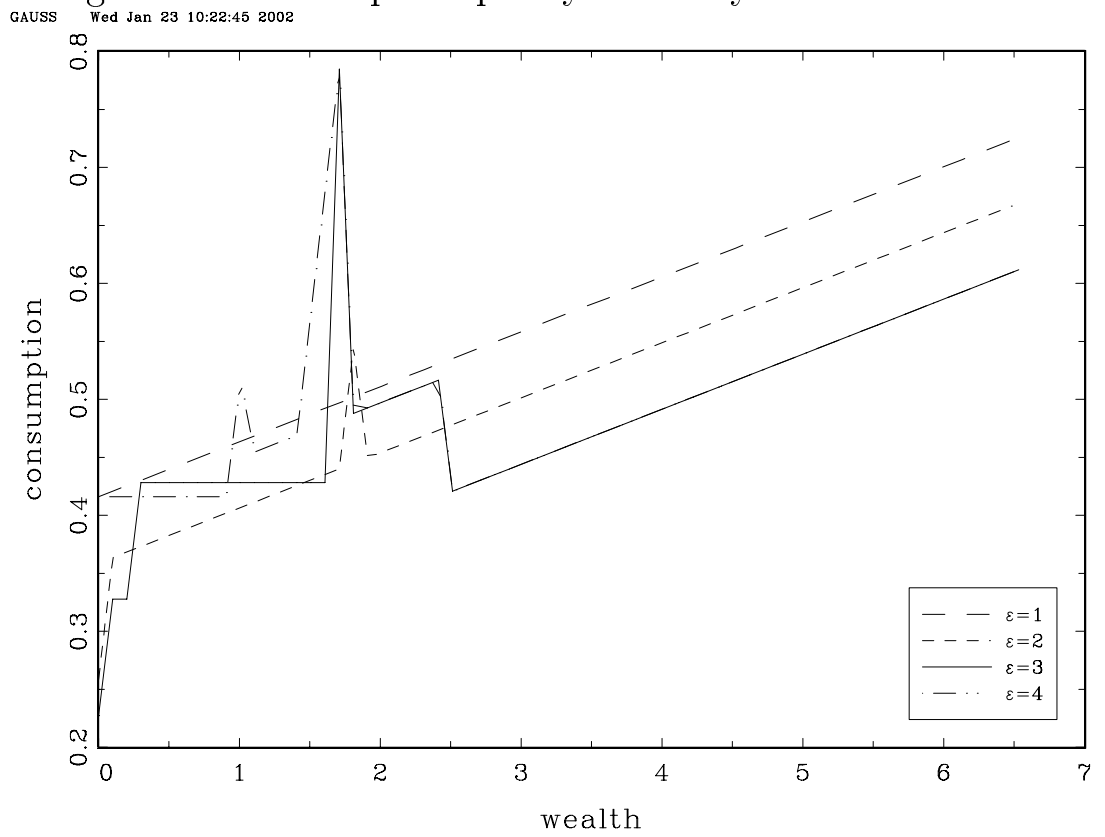

\subsection{Equilibrium Properties}

In this section, we discuss the properties of the benchmark equilibrium. The optimal consumption policy of the agents and the wealth distribution are described in turn. The consumption policies of 20-year old workers with productivity $j=2$ are illustrated in figure $1 .{ }^{17}$ For the employed worker (upper dashed line), consumption is an increasing function of wealth. For unemployed workers, however, consumption has a peak and the marginal propensity to consume out of wealth is even declining over an intermediate range of wealth. In order to pass the means test of unemployment assistance in the following year, shortterm unemployed agents with employment status $\epsilon=2(\epsilon=3)$ increase their consumption drastically at a wealth level of approximately $k=1.9(k=1.8)$. For this kind of policy, agents choose a next-period capital stock $k^{\prime}(k, \epsilon, j, t)$ below $k_{U A}^{\max }$. Similarly, agents entitled to unemployment assistance in the present period, $\epsilon=3$, and the unemployed agent who is not entitled to unemployment insurance or assistance, $\epsilon=4$, have a peak in consumption at the wealth level $k=1.0$ and $k=1.8$, respectively, ensuring a next-period wealth level below the allowable one $k_{W}^{\max }$ specified in the means test of welfare payments. Notice

\footnotetext{
${ }^{17}$ The consumption policy of the workers with different age $t$ and productivity class $j$ is qualitatively the same as the one displayed in figure 1.
} 
further that consumption of unemployed agents $(\epsilon=2,3)$ increases sharply for low levels of wealth as agents are liquidity-constrained.

Average consumption of all agents amounts to 1.075 units of the consumptioninvestment good and is an increasing function of age (not illustrated). The consumptionage profile differs from the one in İmrohoroğlu et al. (1995), who find a hump-shaped consumption path in their life-cycle economy with liquidity constraints. İmrohoroğlu et al. study the effects of a change in the public pensions on economic welfare and, similar to our model, the subjective discount rate of the households is smaller than the interest rate in the economy. However, contrary to our model, İmrohoroğlu et al. assume lifetime to be uncertain. For this reason, preferences for consumption decline in old age in their model. ${ }^{18}$ A hump-shaped consumption-age profile is more realistic. ${ }^{19}$ In our model, however, high old-age consumption increases the incentives to save for retirement and increases the capital stock; a similar effect would be present if we modeled the need to save for precautionary savings (e.g. for uncertain medical expenditures) or for leaving bequests.

Average wealth amounts to $K=5.204$. The age-wealth profile is hump-shaped, as typically found in life-cycle models. During the working life of agents, average wealth of each generation increases before it declines after retirement. The distribution of wealth is illustrated by the Lorenz curve in figure 2. In our model, the richest 10 percent of the agents own 30 percent of all wealth, while the poorest $30 \%$ own only $4 \%$ of the assets. The distribution of wealth is more equal than the one observed empirically in the German economy; in our model, the Gini coefficient is equal to $49.5 \%$ and falls short of values close to $59 \%-89 \%$ as reported by Bomsdorf (1989). ${ }^{20}$ There are two important reasons why our model underestimates the degree of asset dispersion: first, we neglect self-employment and business ownership; ${ }^{21}$ second, agents do not leave bequests. ${ }^{22}$

\footnotetext{
${ }^{18}$ In other life cycle models similar to ours, consumption is also an increasing function of age as e.g. in Auerbach et al. (1983).

${ }^{19}$ See, e.g., Hubbard et al., 1995, for empirical evidence in the US.

${ }^{20}$ Bomsdorf analyzes Gini coefficients of the wealth distribution for different kinds of assets in the periods 1973, 1978, and 1983. Within each asset group, Gini coefficients are remarkably stable. The distribution of savings, securities, and real estate in 1983 are characterized by Gini coefficients equal to 0.59, 0.89, and 0.74 , respectively.

${ }^{21}$ Quadrini (1999) introduces entrepreneurship in a dynamic general equilibrium and presents a promising approach in order to explain observed wealth heterogeneity among the very rich agents.

${ }^{22}$ Hubbard/Judd (1987) and Heer (2001) also consider bequests in their analysis of a life-cycle model.
} 
Figure 2: Lorenz curve for benchmark case

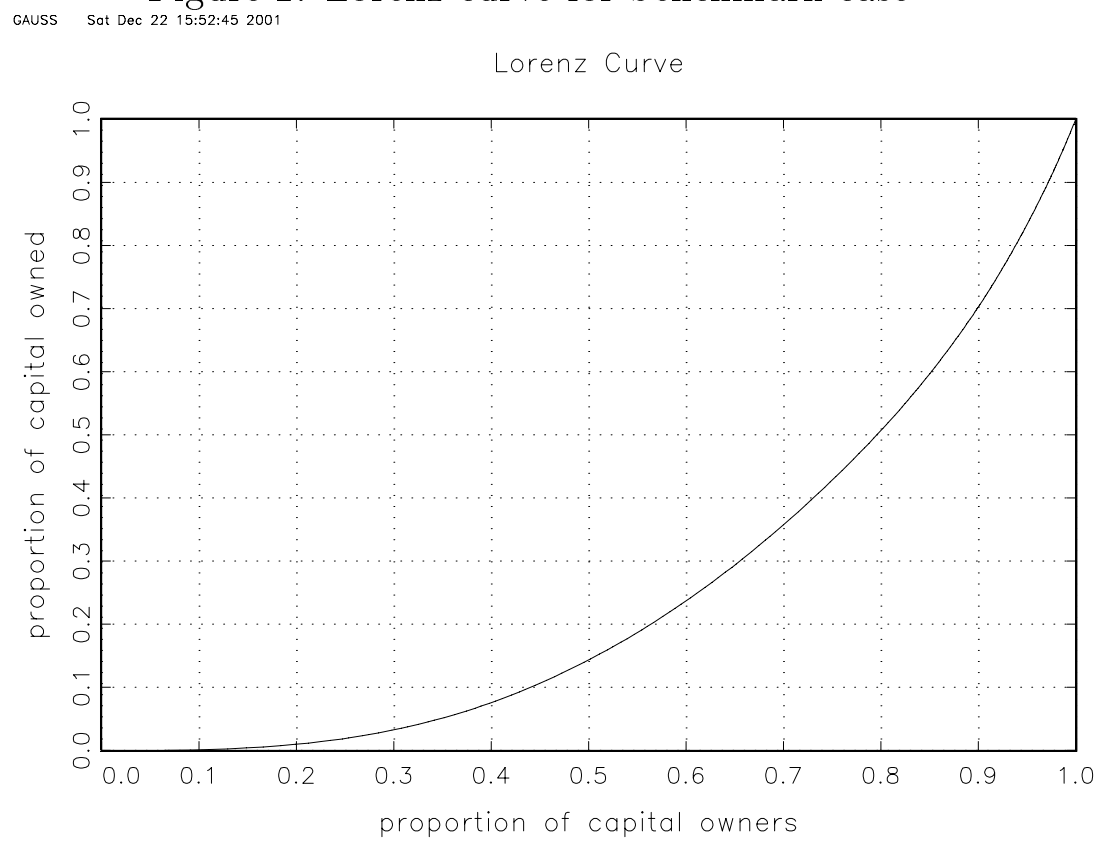

In our benchmark economy, the unemployment rate amounts to $9.22 \% ; 3.94 \%$ of the workforce are unemployment insurance recipients, $2.21 \%$ are entitled to unemployment assistance, while the number of welfare recipients amounts to $3.06 \%$. In 1995, the ratio of unemployment insurance recipients relative to unemployment assistance recipients was only slightly higher in West Germany and amounted to 0.82. Furthermore, the number of welfare recipients aged 18-65 relative to the number of unemployment compensation recipients amounted to 0.51 in Germany, while the equivalent number in our model is approximately the same, $n_{W} /\left(n_{U I}+n_{U A}\right)=0.50$.

For numerical welfare comparison purposes, our point of reference will be the economy with complete earnings insurance and no means test. With full insurance, precautionary savings decrease implying an aggregate wealth of $K=4.939$. Steady-state welfare is higher in the full-insurance reference economy compared to the one of our benchmark calibration

In Hubbard/Judd (1987), agents have an uncertain lifetime and do not have access to annuity markets. As a consequence, they leave bequests which are assumed to be redistributed lump-sum to the 20-year old agents. Heer (2001) explicitly accounts for a parent-child link and parents also leave voluntary bequests to their children. Our focus of interest, however, is the effect of unemployment compensation on the wealth distribution as originating from earnings uncertainty and the risk of unemployment. Therefore, we refrain from introducing business ownership and bequests into our model keeping the model as simple as possible. 
for the German economy, amounting to a gain in consumption of $\delta_{c}=0.70 \%$. Of course, in the presence of complete earnings insurance, there is no within-generation inequality among the workers of the same skill class. However, the between-generation inequality exceeds the one in our benchmark economy due to the more pronounced decrease of lifecycle savings among the income-poor workers relative to the one among the income-rich workers. Therefore, the Gini coefficient (coefficient of variation) for the economy with complete earnings insurance amounts to $51.05 \%$ (0.9452). In the following, the institutional features of the German unemployment compensation system are analyzed with respect to its abilities to provide for a more equal distribution of wealth and a higher welfare.

\subsection{Optimal Replacement Ratios}

In this section, a change in the benefit level of unemployment insurance, unemployment assistance, and welfare payments is analyzed. Table 3 presents our results for the unemployment insurance payments $w_{U I}$. Each row in table 3 represents a different unemployment compensation arrangement $\Omega$. The first two columns give the absolute amount of unemployment insurance payments per efficiency unit $\eta_{j, t}$ and the replacement ratio, respectively, and the remaining columns contain the equilibrium values of aggregate variables, the Gini coefficient, the coefficient of variation $\mathrm{CV}$, and the consumption equivalent increase $\delta_{c}$ associated with the policy $\Omega$. Our benchmark calibration of the German economy is given by the replacement ratio $z_{U I}=50 \%$ corresponding to $w_{U I}=0.530$.

As discussed in the introduction, most theoretical studies concede that social security decreases earnings uncertainty and hence precautionary savings. Contrary to these studies, however, we distinguish three benefit kinds of unemployment compensation and consider age-dependent probabilities of unemployed workers to have a job in the following period. For example, an unemployed agent at working age 30 will be unemployed for another period with probability $1-p(30)=63.9 \%$. Following an increase of unemployment insurance, employed agents will decrease precautionary savings on the one hand. ${ }^{23}$ On the other hand, short-term unemployed workers have a high probability to be unemployed next period as well and will save a higher proportion of their income than the employed agents.

\footnotetext{
${ }^{23}$ In addition, the employed agent's net labor income decreases slightly because the income tax rate $\tau$ increases.
} 
Table 3: Unemployment insurance $w_{U I}$, savings, and distribution

\begin{tabular}{cc|ccccccc}
\hline & & & & & & & & \\
$w_{U I}$ & $\zeta_{U I}$ & $K$ & $w$ & $\tau$ & $\bar{c}$ & Gini & $\mathrm{CV}$ & $\delta_{c}$ \\
\hline & & & & & & & & \\
0.108 & 0.1 & 5.300 & 1.389 & $22.21 \%$ & 1.079 & $48.24 \%$ & 0.889 & $-1.22 \%$ \\
0.215 & 0.2 & 5.289 & 1.388 & $22.46 \%$ & 1.079 & $48.43 \%$ & 0.892 & $-1.07 \%$ \\
0.321 & 0.3 & 5.267 & 1.386 & $22.71 \%$ & 1.078 & $48.75 \%$ & 0.897 & $-0.97 \%$ \\
0.426 & 0.4 & 5.245 & 1.383 & $22.97 \%$ & 1.077 & $48.89 \%$ & 0.890 & $-0.81 \%$ \\
0.530 & 0.5 & 5.204 & 1.380 & $23.22 \%$ & 1.075 & $49.49 \%$ & 0.910 & $-0.70 \%$ \\
0.633 & 0.6 & 5.178 & 1.377 & $23.47 \%$ & 1.074 & $49.82 \%$ & 0.916 & $-0.61 \%$ \\
0.734 & 0.7 & 5.142 & 1.375 & $23.72 \%$ & 1.072 & $50.01 \%$ & 0.920 & $-0.51 \%$ \\
0.836 & 0.8 & 5.135 & 1.374 & $23.96 \%$ & 1.072 & $50.08 \%$ & 0.921 & $-0.42 \%$ \\
0.936 & 0.9 & 5.130 & 1.373 & $24.21 \%$ & 1.072 & $50.12 \%$ & 0.922 & $-0.35 \%$ \\
1.037 & 1.0 & 5.118 & 1.373 & $24.44 \%$ & 1.071 & $50.26 \%$ & 0.924 & $-0.30 \%$ \\
\hline
\end{tabular}

Hence, a redistribution of income from the employed to the unemployed agents increases savings for the latter reason. The total effect of an increase of UI payments on aggregate savings is negative for the German calibration for $\zeta_{U I} \in[0.1,1.0]$; aggregate wealth $K$ is a decreasing function of unemployment insurance $w_{U I} \cdot{ }^{24}$ The effect of unemployment insurance payments $w_{U I}$ on aggregate wealth $K$ is significant. Following an increase of UI benefits from the present level with replacement ratio $\zeta_{U I}=50 \%$ to one of complete insurance, $\zeta_{U I}=100 \%$, aggregate wealth $K$ falls by $1.7 \%$. In order to finance the additional UI payments, the government has to increase its income tax $\tau$ from $23.22 \%$ to $24.44 \%$.

The increase of unemployment insurance payments also results in a higher concentration of wealth. Following an increase of the unemployment insurance replacement ratio from $50 \%$ to $100 \%$, the Gini coefficent (coefficient of variation) increases from $49.5 \%$ (0.910) to $50.3 \%$ (0.924). The provision of higher unemployment compensation decreases precautionary savings of the low income quintiles $(j=1,2)$ by a higher percentage than those of the higher income quintiles $(j=4,5)$. Higher unemployment insurance, however, increases steady-state welfare, as measured by (29). The consumption equivalent increase following a policy change from $z_{U I}=50 \%$ to $z_{U I}=100 \%$ amounts to $\delta_{c}=0.40 \%$, and complete

\footnotetext{
${ }^{24}$ This result depends crucially on the assumption of a hump-shaped age-earnings profile. For a flat age-earnings profile with $\kappa_{1}^{j}=\kappa_{2}^{j}=0$, wealth is even an increasing function of unemployment insurance $w_{U I}$.
} 
Table 4: Unemployment assistance $w_{U A}$, savings, and distribution

\begin{tabular}{cc|ccccccc}
\hline$w_{U A}$ & $\zeta_{U A}$ & $K$ & $w$ & $\tau$ & $\bar{c}$ & Gini & $\mathrm{CV}$ & $\delta_{c}$ \\
\hline 0.108 & 0.1 & 5.424 & 1.400 & $23.02 \%$ & 1.085 & $47.17 \%$ & 0.866 & $-0.58 \%$ \\
0.214 & 0.2 & 5.346 & 1.393 & $23.07 \%$ & 1.081 & $48.00 \%$ & 0.882 & $-0.55 \%$ \\
0.320 & 0.3 & 5.292 & 1.389 & $23.12 \%$ & 1.079 & $48.67 \%$ & 0.893 & $-0.66 \%$ \\
0.466 & 0.44 & 5.204 & 1.380 & $23.22 \%$ & 1.075 & $49.49 \%$ & 0.910 & $-0.70 \%$ \\
0.633 & 0.6 & 5.145 & 1.375 & $23.33 \%$ & 1.072 & $49.91 \%$ & 0.918 & $-0.77 \%$ \\
0.838 & 0.8 & 5.067 & 1.369 & $23.51 \%$ & 1.070 & $50.26 \%$ & 0.926 & $-0.84 \%$ \\
1.041 & 1.0 & 5.043 & 1.365 & $23.69 \%$ & 1.068 & $50.30 \%$ & 0.927 & $-0.93 \%$ \\
\hline
\end{tabular}

insurance is optimal for $\zeta_{U I} \in[0,1]$.

Table 4 summarizes the effects of unemployment assistance on the economy. In the presence of the asset-based means test, a change in the unemployment assistance level has an additional effect on unemployed agents' savings compared with the effects of a change in unemployment insurance payments. For higher levels of unemployment assistance $w_{U A}$, it is optimal to dissave drastically for a wider range of wealth in order to be eligible for unemployment assistance in the following period. As a consequence, the effect of an increase of unemployment assistance payments $w_{U A}$ on the savings of the unemployed workers is more pronounced and the decrease in the capital stock $K$ is more marked than in the case of the unemployment insurance benefit level $w_{U I}$. An increase of UA payments from $w_{U A}=0.466$ to $w_{U A}=1.041$ with corresponding replacement ratios of $44 \%$ and $100 \%$, respectively, results in a reduction of the capital stock by $3.8 \%$. In addition, higher unemployment assistance, even though it redistributes income from the employed to the unemployed agents, increases inequality as measured by the Gini coefficent or the coefficient of variation. Notice that it is optimal to reduce the replacement ratio of unemployment assistance $\zeta_{U A}$ to $20 \%$ for the present unemployment compensation scheme $\left\{\zeta_{U I}, \zeta_{W}, k_{U I}^{\max }, k_{W}^{\max }\right\}$. Complete insurance against long-term unemployment is not optimal in the presence of asset-based means tests and heterogenous earnings. Quantitative welfare effects from a change to the optimal unemployment assistance level amount to $0.15 \%$ of total consumption.

So far, we have only studied a change of the replacement ratios $\zeta_{U I}$ and $\zeta_{U A}$ in iso- 
Table 5: Welfare payments $w_{W}$, savings, and distribution

\begin{tabular}{cc|ccccccc}
\hline$w_{W}$ & $\zeta_{W}$ & $K$ & $w$ & $\tau$ & $\bar{c}$ & Gini & $\mathrm{CV}$ & $\delta_{c}$ \\
\hline & & & & & & & & \\
0.060 & 0.1 & 5.238 & 1.383 & $23.16 \%$ & 1.076 & $49.37 \%$ & 0.907 & $-4.52 \%$ \\
0.120 & 0.2 & 5.220 & 1.382 & $23.19 \%$ & 1.075 & $49.46 \%$ & 0.908 & $-2.12 \%$ \\
0.179 & 0.3 & 5.204 & 1.380 & $23.22 \%$ & 1.075 & $49.49 \%$ & 0.910 & $-0.70 \%$ \\
0.238 & 0.4 & 5.195 & 1.379 & $23.24 \%$ & 1.075 & $49.50 \%$ & 0.910 & $-0.58 \%$ \\
0.297 & 0.5 & 5.168 & 1.377 & $23.28 \%$ & 1.074 & $49.57 \%$ & 0.912 & $-0.47 \%$ \\
0.591 & 1.0 & 5.109 & 1.371 & $23.47 \%$ & 1.072 & $49.70 \%$ & 0.916 & $-0.16 \%$ \\
\hline
\end{tabular}

lation keeping the other parameters of the unemployment scheme fixed. Varying the two unemployment compensation replacement ratios simultaneously, the optimal unemployment compensation scheme $\left\{\zeta_{U I}, \zeta_{U A}\right\}$ is found to be insenstive with regard to both the assumption of asset based means tests and the level of welfare payments $w_{W}$. In particular, we find the optimum replacement ratios to amount to $\left(\zeta_{U I}, \zeta_{U A}\right)=(100 \%, 20 \%)$. This is an important result. Full unemployment compensation is not optimal independent of the presence of asset-based means testing, and optimal unemployment compensation is declining over time as long-term benefits $w_{U A}$ depress savings more markedly than short-term benefits $w_{U I}$.

Next consider table 5 for the analysis of welfare payments. There are four opposing effects of welfare payments on aggregate savings: (i) precautionary savings are reduced for all kinds of agents. (ii) Income is redistributed from the rich to the very poor. (iii) An increase of the welfare benefit level also induces a higher proportion of unemployed agents to dissave drastically in order to pass the means test. And (iv), the liquidity constraint is less binding, especially for the young workers who have not found a job previously. Aggregate savings $K$ are found to be a decreasing function of the level of welfare benefits. Interestingly, for higher welfare payments, the inequality of wealth distribution increases, even though welfare payments redistribute income from the rich to the poor. Following an increase in welfare benefits, the asset limit $k_{W}^{\max }$ becomes a more efficient barrier to the accumulation of wealth among the poor, while the reduction of precautionary savings among the rich agents is negligible. It is welfare-improving to raise welfare payments above the benefit level $w_{W}$ of our benchmark case. For welfare benefits $w_{W}$ equal to the average net wage of the lowest skill class, $(1-\tau) w \bar{\eta}_{1}$, (corresponding to $\zeta_{W}=1$ ), welfare gains of 
Table 6: Asset limit $k_{U A}^{\max }$ on unemployment assistance

\begin{tabular}{c|ccccccc}
\hline$k_{U A}^{\max }$ & $K$ & $w$ & $\tau$ & $\bar{c}$ & Gini & $\mathrm{CV}$ & $\delta_{c}$ \\
\hline & & & & & & & \\
1.0 & 5.211 & 1.381 & $23.18 \%$ & 1.075 & $49.45 \%$ & 0.908 & $-0.72 \%$ \\
2.12 & 5.204 & 1.380 & $23.22 \%$ & 1.075 & $49.49 \%$ & 0.910 & $-0.70 \%$ \\
4.0 & 5.140 & 1.374 & $23.38 \%$ & 1.072 & $49.61 \%$ & 0.914 & $-0.67 \%$ \\
6.0 & 5.135 & 1.374 & $23.40 \%$ & 1.072 & $49.65 \%$ & 0.915 & $-0.65 \%$ \\
$\infty$ & 5.085 & 1.369 & $23.74 \%$ & 1.069 & $49.29 \%$ & 0.909 & $-0.75 \%$
\end{tabular}

$0.54 \%$ of total consumption accrue. ${ }^{25}$

\subsection{Asset-Based Means Tests}

Asset-based means tests have two opposing effects on aggregate savings and distribution. First, for low asset limits, redistribution of wealth is directed to the very poor. Second, asset limits impose an implicit wealth tax of $100 \%$ on some unemployed agents. With increasing asset limits, these agents are characterized by higher levels of wealth and the very poor have higher incentives to save because they do not face the risk to loose entitlement to unemployment compensation. As presented in tables 6 and 7, aggregate savings $K$ fall with both asset limits $k_{U A}^{\max }$ and $k_{W}^{\max }$, while the equality of the wealth distribution, as measured by the Gini coefficient and the coefficient of variation CV, is not a monotone function of the asset limits. With less binding asset limits, wealth-poor unemployed agents increase their savings and the distribution becomes more equal for asset limits $k_{U A}^{\max }$ and $k_{U I}^{\max }$ exceeding the average wealth holding $K$ in the economy.

The potential welfare losses from abandoning asset-based means tests on welfare payments are negligible and amount to $0.03 \%$ of total consumption, while our results

\footnotetext{
${ }^{25}$ We do not analyze welfare payments with a replacement ratio in excess of $\zeta_{W}=100 \%$; we consider the economic costs (in terms of increased unemployment, even though not modeled) of welfare payments $w_{W}$ in excess of the average wage of the lowest efficient group, $(1-\tau) w \bar{\eta}_{1}$, to be prohibitive.
} 
Table 7: Asset limit $k_{W}^{\max }$ on welfare benefits

\begin{tabular}{c|ccccccc}
\hline$k_{W}^{\max }$ & $K$ & $w$ & $\tau$ & $\bar{c}$ & Gini & $\mathrm{CV}$ & $\delta_{c}$ \\
\hline & & & & & & & \\
1.0 & 5.203 & 1.380 & $23.15 \%$ & 1.075 & $49.47 \%$ & 0.910 & $-0.73 \%$ \\
1.38 & 5.204 & 1.380 & $23.17 \%$ & 1.075 & $49.49 \%$ & 0.910 & $-0.70 \%$ \\
2.0 & 5.191 & 1.379 & $23.23 \%$ & 1.074 & $49.56 \%$ & 0.912 & $-0.68 \%$ \\
4.0 & 5.167 & 1.377 & $23.25 \%$ & 1.074 & $49.48 \%$ & 0.911 & $-0.67 \%$ \\
6.0 & 5.154 & 1.375 & $23.27 \%$ & 1.073 & $49.44 \%$ & 0.911 & $-0.71 \%$ \\
$\infty$ & 5.152 & 1.375 & $23.34 \%$ & 1.074 & $49.39 \%$ & 0.909 & $-0.73 \%$ \\
\hline
\end{tabular}

suggest that it is not optimal to abandon asset-based means tests on unemployment assistance. The main reason for this result is provided by the fact that, in our model, most welfare recipients are young workers who are liquidity-constrained and have not found a job previously; therefore, the number of unemployed workers who do not pass the asset means test for welfare payments is small. Long-term unemployed workers entitled to unemployment assistance, however, are those agents who have been previously employed and, hence, have been able to self-insure themselves against the risk of unemployment by building up savings for bad times. The joint optimal unemployment scheme $\left\{\zeta_{U I}, \zeta_{U A}, \zeta_{W}, k_{U A}^{\max }, k_{W}^{\max }\right\}$ with $\zeta_{U I}, \zeta_{U A}, \zeta_{W} \in[0,100 \%]$ and $0 \leq k_{U A}^{\max }, k_{W}^{\max } \leq \infty$ is given by $\left\{\zeta_{U I}, \zeta_{U A}, \zeta_{W}, k_{U A}^{\max }, k_{W}^{\max }\right\}=\{100 \%, 20 \%, 100 \%, 4.0,5.0\}$. The steady-state welfare gain from such a policy amounts to $1.07 \%$ of total consumption compared to the benchmark case $\left\{\zeta_{U I}, \zeta_{U A}, \zeta_{W}, k_{U A}^{\max }, k_{W}^{\max }\right\}=\{50 \%, 44 \%, 30 \%, 2.12,1.38\}$.

\section{Conclusion}

Our model studies the effects of the German unemployment compensation system on distribution, aggregate savings, and aggregate welfare. The following institutional features of the German system are emphasized. First, three kinds of benefits can be distinguished: unemployment insurance payments, unemployment assistance payments, and welfare payments. Second, unemployment assistance and welfare payments are subject to an assetbased means test. And third, the probability of being employed in the next period is lower for unemployed workers than for employed workers and decreasing with age. Considering these institutional features in a general equilibrium life-cycle model, our results can be 
summarized as follows. First, an increase of unemployment compensation decreases savings and aggregate wealth unanimously. Second, complete earnings insurance is optimal for the short-term unemployed workers, but not for the long-term unemployed workers. Third, the equality of wealth distribution is not necessarily increasing with the level of benefits. And fourth, asset-based means tests are not an appropriate instrument for the reduction of wealth inequality, but abandonning them may result in small welfare losses.

In our model, employment is exogenous and the probabilities to find a job and to get separated from a job are given. The provision of unemployment insurance, however, is likely to increase the equilibrium level of unemployment and, consequently, optimal replacement ratios should be lower than those found in our study. For one reason, the government is unable to monitor the unemployed agent's behavior perfectly introducing moral hazard into the decision of an agent to accept a job offer. This aspect of unemployment insurance is studied by Hansen and İmrohoroğlu (1992) showing that the presence of moral hazard results in a significant decrease of the optimal replacement ratio of unemployment insurance. For a second reason, the reservation wage of workers or unions increases with the level of unemployment benefits resulting in higher wages and less employment. Costain (1997) examines a model of search unemployment with endogenous wage bargaining. In his life-cycle model calibrated with regard to the characteristics of the US economy, equilibrium unemployment increases from $5.9 \%$ to $10.5 \%$ following an increase of the replacement ratio from $13 \%$ to $78 \%$. Since our study focuses on the effect of unemployment compensation on savings, our optimal replacement ratios should be interpreted carefully and rather considered as an upper bound.

\section{Appendix}

\section{Computation}

The model has no analytical solution. Algorithms to solve heterogenous-agent model with an endogenous distribution have only recently been introduced in the economic literature. Notable studies in this area are Aiyagari (1994), Costain (1997), den Haan (1996), Huggett (1993), İmrohoroğlu et al. (1995), and Rios-Rull (1996). Like most of these studies, we will only focus on the steady state of the model. Our algorithm follows İmrohoroğlu et 
al. (1995) and Costain (1997) who also perform a numerical analysis of a life-cycle model. The solution algorithm is described by the following steps:

1. Choose the policy parameters $w_{U I}, w_{U A}, w_{W}, w_{R}, k_{U A}^{\max }$, and $k_{W}^{\max }$.

2. Calculate aggregate effective employment $N$.

3. Make initial guesses of $K$ and $\tau$.

4. Compute $w$ and $r$ from the firm's Euler equations.

5. Compute the household's decision functions by backwards induction.

6. Compute the steady-state distribution of assets and entitlement to social security.

7. Compute the values $K$ and $\tau$, that solve the government budget and the aggregate consistency conditions. Check whether the assets holdings are equal to the guessed $K$ and $\tau$. Otherwise update $K$ and $\tau$ and return to step 4 .

In step 5, a simple finite-time dynamic programming problem is solved by iterating the value function $V(k, \epsilon, j, t)$ of a $t$-year old household with capital holdings $k$, employment status $\epsilon$, and skill level $j$. The dynamic program has four state variables: $k, \epsilon, j$, and $t$. We divide the feasible range $\left[0, k^{\max }\right]$ for capital $k$ in each period into 2000 nodes. The upper bound on capital $k^{\max }=20$ corresponds to about four times the average holding of capital and is not binding in our numerical computations. The decision rules of generation $t$ can be found by a single recursion working backwards from the last period of life. In step 6, the steady-state distribution is computed by forward iteration starting with the 1-year old who has no wealth and given employment probability $\mathrm{p}(1)$. A more detailed description of numerical details can be found in İmrohoroğlu et al. (1995).

\section{References}

Aiyagari, S.R., Uninsured Idiosyncratic Risk and Aggregate Saving, Quarterly Journal of Economics, CIX, 659-84, 1994.

Attansio, O.P. and G. Weber, Consumption Growth, the Interest Rate and Aggregation, Review of Economic Studies, 60, 631-49, 1993. 
, Is Consumption Growth Consistent with Intertemporal Optimization? Evidence from the Consumer Expenditure Survey, Journal of Political Economy, 103, 1121-57, 1995.

Auerbach, A.J. and L.J. Kotlikoff, Dynamic Fical Policy, Cambridge University Press, Cambridge, 1987.

Auerbach, A.J., L.J. Kotlikoff, and J. Skinner, The Efficiency Gains from Dynamic Tax Reforms, International Economic Review, 24, 81-100, 1983.

Beaudry, P. and E. van Wincoop, The Intertemporal Elasticity of Substitution: An Exploration using a US Panel of State Data, Economica, 63, 495-512, 1996.

Biewen, M., Income Inequality in Germany during the 1980s and 1990s, Review of Income and Wealth, 46, 1-20, 2000.

Bomsdorf, E., Die personelle Vermögensverteilung in der Bundesrepublik Deutschland 1973, 1978 und 1983, DIW Vierteljahreshefte zur Wirtschaftsforschung, Heft 4, 1989.

Burtless, G., Jobless Pay and High European Unemployment, in: R.Z. Lawrence and C.L. Schultze (eds.), Barries to European Growth. A Transatlantic View, Brookings Institution, Washington, D.C., 1987.

Caballero, R.J., Earnings Uncertainty and Aggregate Wealth Accumulation, American Economic Review, 81, 839-71, 1991.

Campell, J.Y. and N.G. Mankiw, Consumption, Income and Interest Rates: Reinterpreting the Time Series Evidence, in: O.J. Blanchard and S. Fischer (eds.), NBER Macroeconomics Annual, Cambridge, 185-216, 1989.

Caroll, C.D. and A.A. Samwick, How important is precautionary savings, NBER working paper, no. 5194, 1995.

Chaveau, T. and R. Loufir, The Future of Public Pensions in the Seven Major Economies, in: D.P. Broer and J. Lassila (eds.), Pension Policies and Public Debt in Dynamic CGE Models, Physica, Heidelberg, 1997.

Costain, J.S., Unemployment Insurance with Endogenous Search Intensity and Precautionary Saving, Universitat Pompeu Fabra Economics Working Paper, no. 243, 1997.

den Haan, W.J., Understanding equilibrium models with a small and a large number of agents, NBER working paper, no. 5792, 1996.

Dardoni, V., Precautionary savings under income uncertainty: a cross-sectional analysis, Applied Economics, 23, 153-60, 1991.

Drèze, J.H. and F. Modigliani, Consumption decisions under uncertainty, Journal of Economic Theory, 5, 308-35, 1972. 
Fehr, H., Belastungswirkungen der aktuellen Reformvorschläge zur Einkommensbesteuerung und zur Alterssicherung, DIW Vierteljahresbericht zur Wirtschaftsforschung, 362-81, 1997.

Fehr, H., Welfare Effects of Dynamic Tax Reforms, Mohr Siebeck, Tübingen, 1999.

Feist, H. and R. Schöb, Workfare in Germany and the Problem of Vertical Fiscal Externalities, Finanzarchiv, 55, 461-80, 1999.

Flaig, G., Einkommen, Zinssatz und Inflation - Ein Beitrag zur Erklärung von Konsumwachstumsschwankungen, in: G. Bombach, B. Gahlen, and A.E. Ott (eds.), Geldtheorie und Geldpolitik, Tübingen, 1988.

Hansen, G. and A. İmrohoroğlu, The role of unemployment insurance in an economy with liquidity constraints and moral hazards, Journal of Political Economy, 100, 118-42, 1992.

Heer, B., Wealth Distribution and Optimal Inheritance Taxation in Life-cycle Economies with Intergenerational Transfers, Scandinavian Journal of Economics, 103, 445-65, 2001.

Heer, B. and L. Linnemann, Procyclical Labor Productivity: Sources and Implications, Zeitschrift für Wirtschafts- und Sozialwissenschaften, 118, 221-47, 1998.

Hubbard, R.G. and K.L. Judd, Social security and individual welfare: precautionary saving, borrowing constraints, and the payroll tax, American Economic Review, 77, 630-46, 1987.

Hubbard, R.G., J. Skinner, and S.P. Zeldes, The importance of precautionary motives for explaining individual and aggregate saving, in: A. H. Meltzer and C.I. Plosser (eds.), Carnegie Rochester Series on Public Policy, 40, 59-126, 1994.

, Precautionary Saving and Social Insurance, Journal of Political Economy, 103, 360-99, 1995.

Huggett, M., The risk-free rate in heterogenous-agent incomplete-insurance markets, Joural of Economic Dynamics and Control, 17, 953-69, 1993.

Hunt, J., The Effect of Unemployment Compensation on Unemployment Duration in Germany, Journal of Labor Economics, 13, 88-120, 1995.

İmrohoroğlu, A, S. İmrohoroğlu, and D.H. Joines, A life cycle analysis of social security, Economic Theory, 6, 83-114, 1995.

Miller, B.L., The Effect on Optimal Consumption of Increased Uncertainty in Labor Income in the Multiperiod Case, Journal of Economic Theory, 13, 154-67, 1976. 
OECD, Employment Outlook, Paris, July, 1996.

Quadrini, V., Entrepreneurship, Saving and Social Mobility, Pompeu Fabra University working paper, 1999.

Ríos-Rull, J.-V., Life-Cycle Economies and Aggregate Fluctuations, Review of Economic Studies, 63, 465-90, 1996.

Sandmo, A., The effect of uncertainty on savings decision, Review of Economic Studies, 37, 353-60, 1970.

Skinner, J., Risky income, life cycle consumption, and precautionary savings, Journal of Monetary Economics, 22, 237-55, 1998.

Steiner, V., Extended Benefit-Entitlement Periods and the Duration of Unemployment in West Germany, ZEW Discussion Paper, no. 97-14, 1997.

Stokey, N., J.R. Lucas, and E.C. Prescott, Recursive methods in economic dynamics, Harvard University Press, Cambridge, MA, 1989. 